\title{
THE SALSA PROJECT HIGH-END AERIAL 3D CAMERA
}

\author{
W. Rüther-Kindel ${ }^{\text {a, } *}$, J. Brauchle ${ }^{\mathrm{b}}$
}

\begin{abstract}
${ }^{a}$ Dept. of Aeronautical Engineering, University of Applied Sciences Wildau, Germany, WKindel@TH-Wildau.de
${ }^{\mathrm{b}}$ Optical Information Systems at the Robotics and Mechatronics Center (RMC), German Aerospace Center DLR Berlin-Adlershof, Germany, Joerg.Brauchle@DLR.de
\end{abstract}

KEY WORDS: UAV, Scanning System, Digital Terrain Modelling, Modular Payload Concept, Photogrammetric Camera, MACS TumbleCam, Oblique Camera, 3D-Model

\begin{abstract}
:
The ATISS measurement drone, developed at the University of Applied Sciences Wildau, is an electrical powered motor glider with a maximum take-off weight of $25 \mathrm{~kg}$ including a payload capacity of $10 \mathrm{~kg}$. Two $2.5 \mathrm{~kW}$ engines enable ultra short take-off procedures and the motor glider design results in a $1 \mathrm{~h}$ endurance. The concept of ATISS is based on the idea to strictly separate between aircraft and payload functions, which makes ATISS a very flexible research platform for miscellaneous payloads. ATISS is equipped with an autopilot for autonomous flight patterns but under permanent pilot control from the ground. On the basis of ATISS the project SALSA was undertaken. The aim was to integrate a system for digital terrain modelling. Instead of a laser scanner a new design concept was chosen based on two synchronized high resolution digital cameras, one in a fixed nadir orientation and the other in a oblique orientation. Thus from every object on the ground images from different view angles are taken. This new measurement camera system MACS-TumbleCam was developed at the German Aerospace Center DLR Berlin-Adlershof especially for the ATISS payload concept. Special advantage in comparison to laser scanning is the fact, that instead of a cloud of points a surface including texture is generated and a high-end inertial orientation system can be omitted. The first test flights show a ground resolution of $2 \mathrm{~cm}$ and height resolution of $3 \mathrm{~cm}$, which underline the extraordinary capabilities of ATISS and the MACS measurement camera system.
\end{abstract}

The project SALSA described in this paper was supported by the federal state Brandenburg and the European Union by the EFRE-WiTet program. More information about the "Europäischer Fond für regionale Entwicklung" EFRE can be found under www.efre.brandenburg.de.

\section{INTRODUCTION}

In autumn 2006 the first UAV project SMAP (Smart Aerial Photogrammetry System) was started at the University of Applied Sciences Wildau. It was based on a fixed wing model aircraft which was available on the market, see Figure 1. The aim was to demonstrate that small UAV are capable to carry a calibrated aerial camera to produce aerial images of a quality comparable to man operated aircraft.

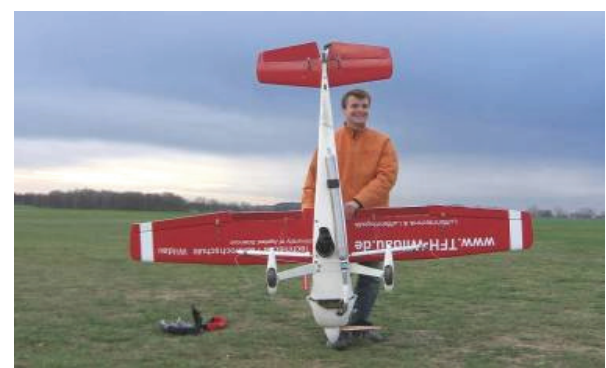

Figure 1. TFH-Bully Demonstrator

A Rollei AIC was integrated in the fuselage together with a navigation system, a board computer and a telemetry system, see Figure 2.

\footnotetext{
* Corresponding author.
}

The project was successfully finished, but showed that the carrier aircraft was not the ideal platform for this kind of missions. Main disadvantages where vibrations from the piston engine and the limited access to the camera system in the narrow fuselage, see Figure 3. In addition the payload of $7 \mathrm{~kg}$ brought the total weight of the airplane to its limits, which resulted in a high landing speed. As a consequence it was decided to develop a new carrier aircraft especial designed for multi role measurement tasks.

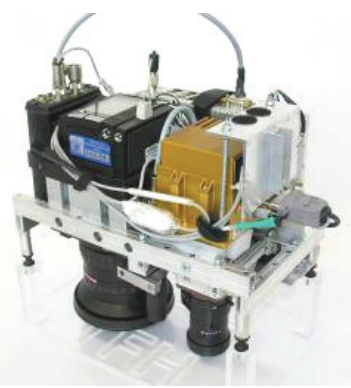

Figure 2. Aerial Camera System SMAP

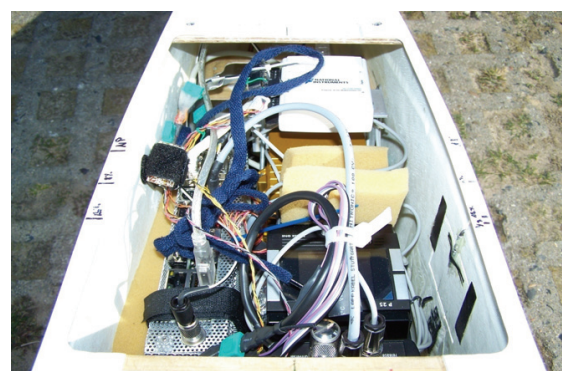

Figure 3. The SMAP Camera System 


\section{THE ATISS MEASUREMENT DRONE}

Based on the experiences of this first project the UAV ATISS (Autonomous Flying Testbed for Integrated Sensor Systems) was designed. The ATISS project was started as an internal university project in spring 2007. The special requirements for this new aircraft where
1. separation of payload and carrier functions
2. electrical propulsion system
3. easy access payload concept
4. motor glider design for low energy consumption
5. low approach speed of $10 \mathrm{~m} / \mathrm{s}$
6. maximum take-off weight of $25 \mathrm{~kg}$
7. payload of $10 \mathrm{~kg}$

Configuration and construction where carried out as a bachelor thesis, see Figure 4.

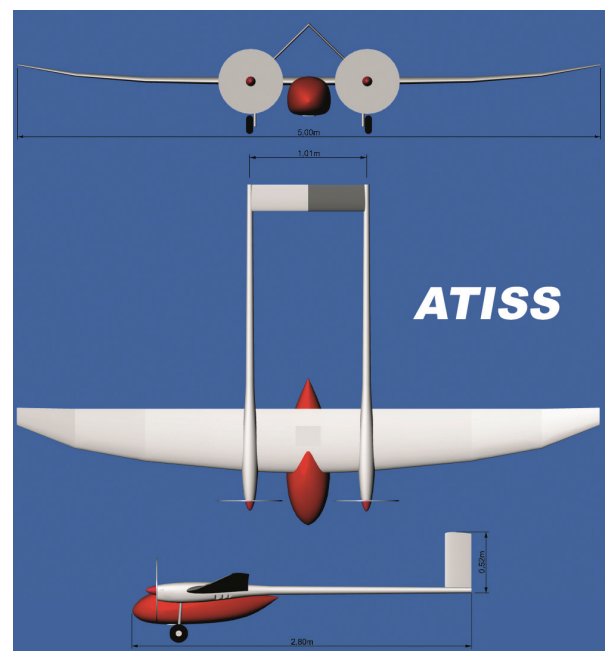

Figure 4. ATISS Design

Production took place in the aeronautics research lab of the working group, see Figure 5. First flight was in summer 2009.
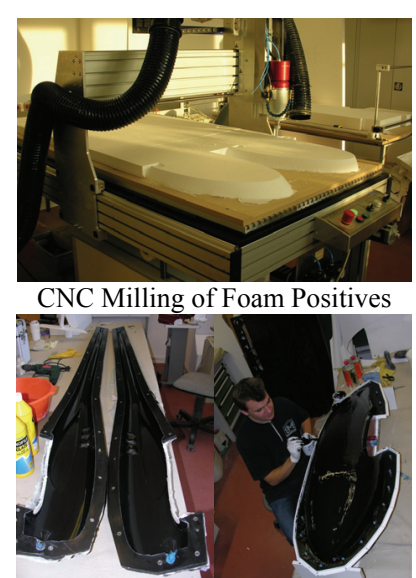

Fuselage and Pod Negatives

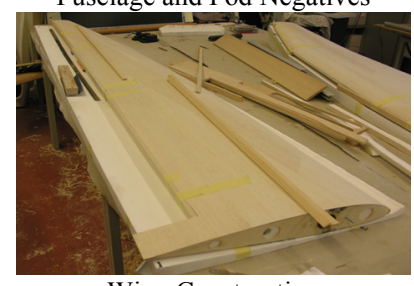

Wing Construction

Figure 5. ATISS Production
The maximum take-off weight of $25 \mathrm{~kg}$ was chosen due to legal restrictions in Germany, but it can be extended if required. The actual payload capacity of $10 \mathrm{~kg}$ gives enough flexibility for a large bandwidth of equipment. Speed range is from $10 \mathrm{~m} / \mathrm{s}$ to $40 \mathrm{~m} / \mathrm{s}$, typical operation speed is $18 \mathrm{~m} / \mathrm{s}$ for an endurance of approximately $1 \mathrm{~h}$, which can be increased by reducing payload.

The modular and easy access payload concept CONTAIN (Concept for Autonomous Operating Aerial Sensor Payloads) is shown in Figure 6 . The rack system offers a payload compartment of $220 \times 220 \times 400 \mathrm{~mm}^{3}$ volume. The rail system enables easy and fast access to the payload.

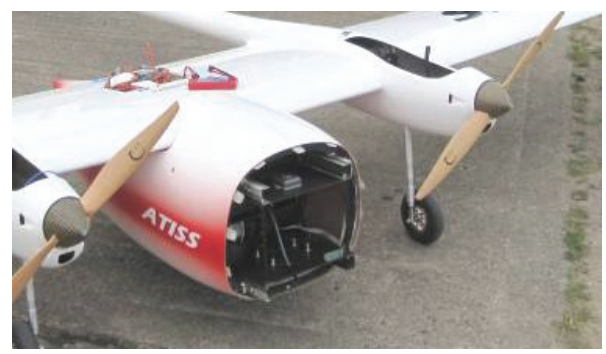

Figure 6. Payload Concept CONTAIN

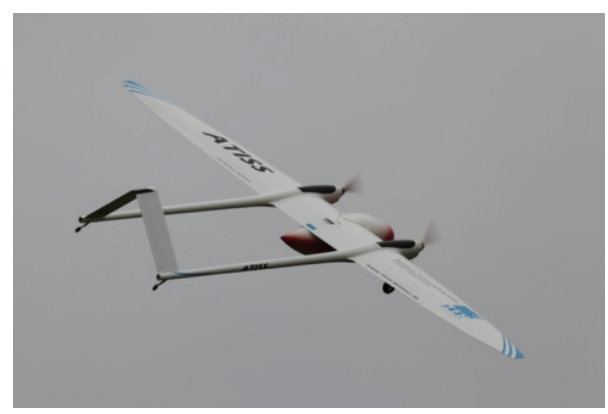

Figure 7. ATISS First Flight

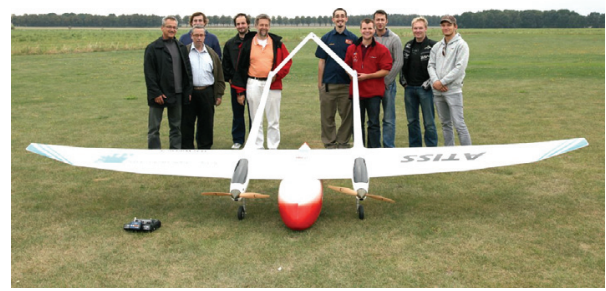

Figure 8. The ATISS Measurement Drone

\section{THE SALSA PROJECT IDEA}

Fabrication of Fuselage and Pod

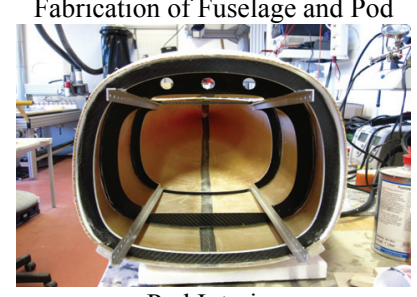

Pod Interior

The SALSA project was initiated from the results of the SMAP project, which demonstrated that a small sized UAV is capable to carry a calibrated professional aerial camera system. The next logical step was to integrate a laser scanner for digital terrain modelling. This was the basic idea when the SALSA project was started at the University of Applied Sciences Wildau in 2009, therefore in the original context SALSA means Smart Airborne Laser Scanner. It was clear that it would be difficult to combine a laser scanner with an aerial camera within the ATISS payload limits of $10 \mathrm{~kg}$. Soon after the project was 
started the technical concept was completely revised. Technical discussions with German Aerospace Center DLR BerlinAdlershof brought the idea, that a new concept design based on two digital cameras would show considerable benefits.

\section{3D AERIAL CAMERA SYSTEM MACS-TUMBLECAM}

Remote sensing on unmanned platforms offers enormous demands for specialized measurement cameras. Ad hoc developed photogrammetric systems are practically lacking. Framework requirements for sophisticated sensor systems are challenging, in particular respective dimensions and weight. The pursuit of higher ground pixel resolution in the centimeter range leads to bring the carrier closer to the target, utilizing smaller electrically powered carriers. One or more circular/linear flight paths over a distinctive object are often shown, followed by computer-based modeling of this object (Küng et al., 2011; Li \& Li, 2011; Wenzel et al., 2013). Flight times of 15 to 30 minutes are common until the need for touch down.

The Institute of Optical Sensor Systems at the German Aerospace Center (DLR) developed the „Modular Airborne Camera Systems (MACS)“, a family of highly specialized and practically applicable aerial cameras (Lehmann et al., 2011). Exercising this concept, featured requirements can be fulfilled.

With MACS-TumbleCam a new method of acquiring oblique images is realized. Thus, the target area of airborne surveys can be increased considerably. Practical demonstration was executed in test flights with the ATISS measurement drone in 2012. High precision geo-information can be derived from this lightweight measurement camera system, e.g. fully texturized 3D-models.

\subsection{Requirements}

As described in chapter 2 the concept of ATISS is based on the strict separation of carrier and payload functions. Thus, a selfsustaining 3D-capable aerial camera system for local area acquisition had to be developed. Dimensions were restricted to $220 \times 220 \times 400 \mathrm{~mm}^{3}$ (W x H x L) with a max. weight of $8 \mathrm{~kg}$. All peripherals like power supply, inertially aided GNSS system and computational devices hat to be integrated into the pod. To enable correct and realistic models of the surveyed area, system's main objective was to acquire best-grade images. Therefore cartographic cameras with high radiometric and geometric resolution, respective their calibration parameters and stable inner orientation are operated. Accurate exterior orientation for any image had to be delivered to assist the postprocessed aerotriangulation (AT). For visualization of preferable realistic façades different perspectives of the target area had to be acquired. Following the fixed wing flight characteristics of ATISS, parallel stripes are to be flown.

\subsection{The tumbling concept}

Caused by these requirements, conventional methods of taking oblique images could not be adopted. Taking a penta-camera head (5 fixed cameras with 1 nadir and 4 main oblique axes) would cost oversized weight, energy consumption and computer capacities. On the other hand, a triple-camera head (3 fixed cameras with 1 nadir and 2 main oblique axes) would reduce the ground coverage by ca. $50 \%$ at a given flight endurance by necessarily crossing the flight lines.

A new approach to catch multiple perspectives by only one camera is given by the tumbling (wobbling) sensor: A measuring camera is biaxial gimbal-mounted and deflected by a carrier pin which is coaxial to the optical axis of the camera. In case of carrier pin's constant distance to the ungimbaled axis, the carrier has the ability to describe a circular path which is the only left degree of freedom. The pin's circular motion can be generated by a rotational drive. Radius of circular path in conjunction with the distance of radius plane to cardanic pivot defines the constant deflection of the camera (Figure 9).

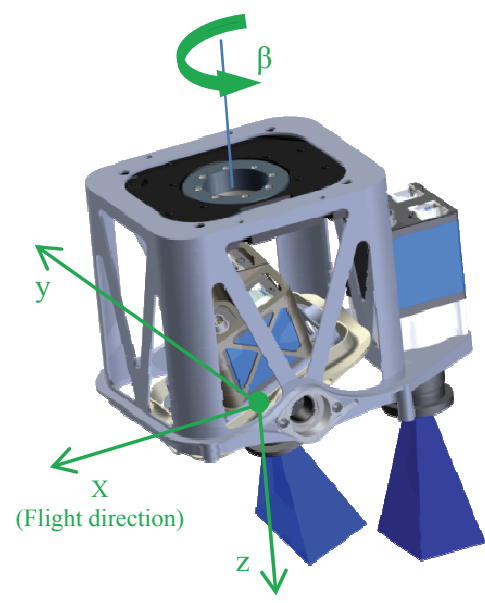

Figure 9. Sensor head with tumbling camera (left) and a nadirpointed camera, coordinate system of sensor head

That way by only one rotational movement not only four major perspectives can be reached, in fact arbitrary perspectives are obtainable (circular around the nadir point). The dependency between gear velocity and camera acquisition rate determines the overlap of two consecutive images.

Rotational direction is switchable, velocity is widely adjustable down to $0 \mathrm{deg} / \mathrm{s}$ and unlimited rotation range allows for endless $\mathrm{n} \times 360$ deg motion. The camera moves tumbling, thus rotation around the optical axis is avoided. Camera cabling is torsionfree. Assembling rotary joints can be waived. Never-ending circulation plays an important role for photogrammetric processing of images: as a result of linear flight path the rotating oblique image footprints become a spiral, yielding to a unseparated image block. Figure 10 shows a constellation of oblique footprints based on real data, here with gear steps of 45 $\mathrm{deg}$ and aircraft crab-angle of ca. $-10 \mathrm{deg}$. The crab-angle can be easily compensated on-the-fly by adjusting the motor's zero point position.

In case of ideal flight trajectory, again by avoiding rotation around the optical axis, the yaw-angle of oblique images persists unaltered. Photogrammetric analysis can be established in complete analogy to common conventional nadir image flights. 


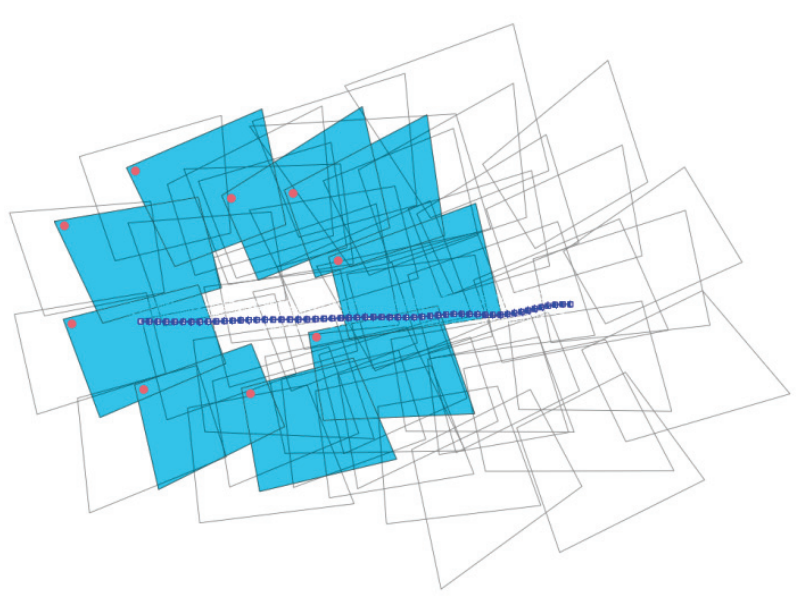

Figure 10. Footprints of a tumbling (wobbling) camera. Blue dots assign the flight path. Red dots mark upper right image corner, thus no rotation around optical axis.

\subsection{MACS-TumbleCam}

Combining nadir camera and oblique oriented tumbling camera, added by peripheral devices, enables a lightweight $3 \mathrm{D}$ aerial camera system (Figure 11). The images can be analyzed on basis of conventional algorithms.

Oblique footprints are circulating around nadir camera's footprints. This results in higher resolution oblique images, because every image has to cover a ground detail, not a quadrant as stated in penta- or triple-systems. Mounted sensors are two 8 megapixel industrial cameras including trigger and event interfaces. Both cameras are identical constructed and take images synchronously.

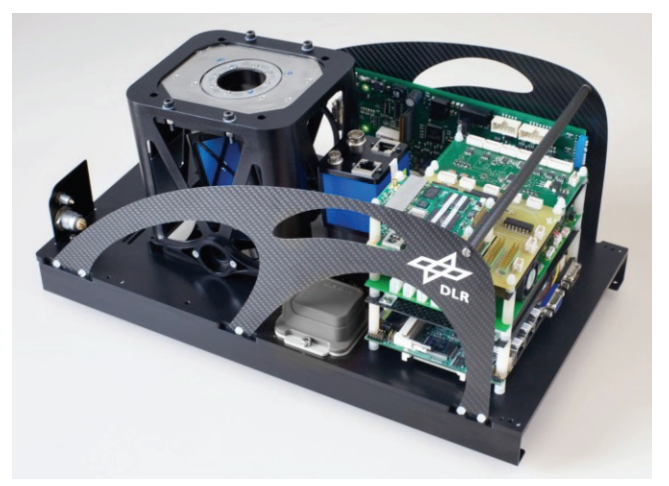

Figure 11. MACS-TumbleCam

With proper overlap of oblique images this block resp. these blocks are ready to be aerotriangulated exclusively. Only a small overlap is necessary using another way: position the images of the nadir camera using AT, then transform the exterior orientation into the synchronously taken oblique image (Wieden \& Stebner, 2013). The boresight correction is described in chapter 2.4. To apply this workaround, defined geometrical reference between both cameras has to be known at the moment of exposure. This geometrical relation arises from construction and gear position. Hence, a rigid frame (shown in Figure 9) for both cameras and the drive was constructed. Nadir camera and motor are mounted stationary. By mirrored spring constraining, the gimballing of tumbling camera is restrained free from float regarding occurring dynamic forces, further any temperature-dependent stretch is compensated. Weight of the frame is $214 \mathrm{~g}$.

Constant oblique deflection was set to an angle in such a matter, that a small overlap between any oblique / nadir photo pair is ensured. Thus, not only an associated image block is established for the images of the first camera and of the second camera, respectively, but also for the images among each of both cameras. By operating only two cameras, an overall aperture angle according to a penta-camera head is gained.

As gear a rotation stage of $14 \mathrm{~mm}$ height and encoder resolution of $34 \mu \mathrm{rad}(0.002 \mathrm{deg})$ is used. For the moment of image integration, the motor arrests and delivers its angular position to the computer. Afterwards, the proximate angle is achieved to acquire the next image.

Mainly by reason of weight restrictions, the direct georeferencing is produced by a MEMS-based GNSS-aided attitude and heading reference system (AHRS) consisting of an 6 degree of freedom IMU, 3D magnetometer and L1 C/A code GNSS receiver. Data are UTC-time stamped with a rate of 120 $\mathrm{Hz}$. Bias stability of the IMU is $1 \mathrm{deg} / \mathrm{s}$ for the gyros and 0.02 $\mathrm{m} / \mathrm{s}^{2}$ for the accelerometers, respectively. Noise figure is 0.05 $\mathrm{deg} / \mathrm{s} / \mathrm{sqrt}(\mathrm{Hz})$ for the gyros and $0.002 \mathrm{~m} / \mathrm{s}^{2} / \mathrm{sqrt}(\mathrm{Hz})$ for the accelerometers, respectively. Built-in magnetometers as well as reliably existing GNSS solution assist the AHRS to compensate the IMU drifts and enables output of earth-referenced Eulerangles roll, pitch and heading.

For AT and 3D modeling, the global geodetic position of any image focal point is of much higher importance. Hence, a L1/L2 GNSS receiver for postprocessing raw measurements including reference stations was conducted. Gained accuracies are shown in chapter 2.5. General set-up of MACS-TumbleCam is collated in Table 1 .

\begin{tabular}{|c|c|}
\hline Imaging sensors & $\begin{array}{l}\text { 2x RGB CCD, } 3296 \times 2472 \text { pixels } \\
\text { each, } 5.5 \mu \mathrm{m} \text { pixel size }\end{array}$ \\
\hline Geometric resolution & $\begin{array}{l}\sim 2 \mathrm{~cm} @ 100 \mathrm{~m} \text { height (above } \\
\text { ground) }\end{array}$ \\
\hline $\begin{array}{l}\text { Radiometric } \\
\text { resolution }\end{array}$ & 12 bit raw image \\
\hline Focal length & $35 \mathrm{~mm}$ each \\
\hline Image rate & $5 \mathrm{~Hz} \max$. \\
\hline Arrangement & $\begin{array}{l}1 \mathrm{x} \text { nadir }+1 \mathrm{x} \text { oblique with tilt angle } \\
\text { of } \sim 30 \text { deg and arbitrary rotation }\end{array}$ \\
\hline $\begin{array}{l}\text { Actuator tumbling } \\
\text { camera }\end{array}$ & $\begin{array}{l}\text { Rotational stage, } 34 \mu \mathrm{rad} \text { encoder } \\
\text { resolution }\end{array}$ \\
\hline Direct georeferencing & $\begin{array}{lccc}\begin{array}{l}\text { Postprocessed } \\
\text { MEMS AHRS }\end{array} & \text { GNSS } & + \\
\end{array}$ \\
\hline $\mathrm{PC}$ & $\begin{array}{l}3.5 " \text { single board, Atom D525, } \\
\text { Linux, } 2 \text { x } 256 \text { GB SSD }\end{array}$ \\
\hline Onboard recording & $\sim 40,000$ images \\
\hline Telemetry & $868 \mathrm{MHz}$ \\
\hline Dimensions & $400 \times 220 \times 200 \mathrm{~mm}^{3}(\mathrm{~L} \times \mathrm{W} \times \mathrm{H})$ \\
\hline Weight & $<4 \mathrm{~kg}(<5 \mathrm{~kg}$ with LiPo battery) \\
\hline Power supply & $\begin{array}{l}\text { LiPo battery for } 1 \mathrm{~h} \text { operation, or 9- } \\
36 \text { VDC }\end{array}$ \\
\hline
\end{tabular}

Table 1. Setup MACS-TumbleCam 


\subsection{Geometrical accuracy}

The geometrical reference between nadir camera and oblique camera requires leverarms and the angular offsets in dependency of gear position. Leverarms are determined directly from the CAD-model. Angular offsets are calculated using the trivial formulas

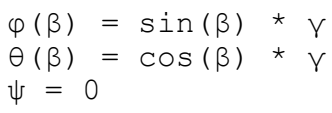

where

$\varphi$ (roll), $\theta$ (pitch) and $\psi($ yaw) $=$ rotation angles around the sensor head coordinate frame axes $x, y$ and $z$ (see Figure 9),

$\beta=\quad$ motor position and

$\gamma=\quad$ deflection angle of oblique camera (30 deg).

Furthermore, exact angular correction values (adjust-boresights) have to be adopted, which are gear-position dependent. These values are a result of manufacturing and assembly imprecisions, tolerances within the kinematic chain and angular encoder uncertainty. The adjust-boresights have been examined photogrammetrically using the mathematical principle of projective reconstruction. A calibrated camera Canon EOS 5D was fixed to the sensor head frame. Its images played the role of joining the hardly overlapping images of nadir and oblique camera. The catenation images were static and covered the footprint of all possible oblique footprints. Consequently they covered the nadir camera's footprint. The motor turned in steps of $5 \mathrm{deg}$. At every stop, the images of all 3 cameras were taken instantly. For analyzing repeat accuracy 5 full circles were passed through, leading to 361 image triplets. Executing block matching (Mathworks, 2013) on each of the static camera images did show that these cameras did not change their orientation in fact. Thus, one single catenation image could be used as reference.
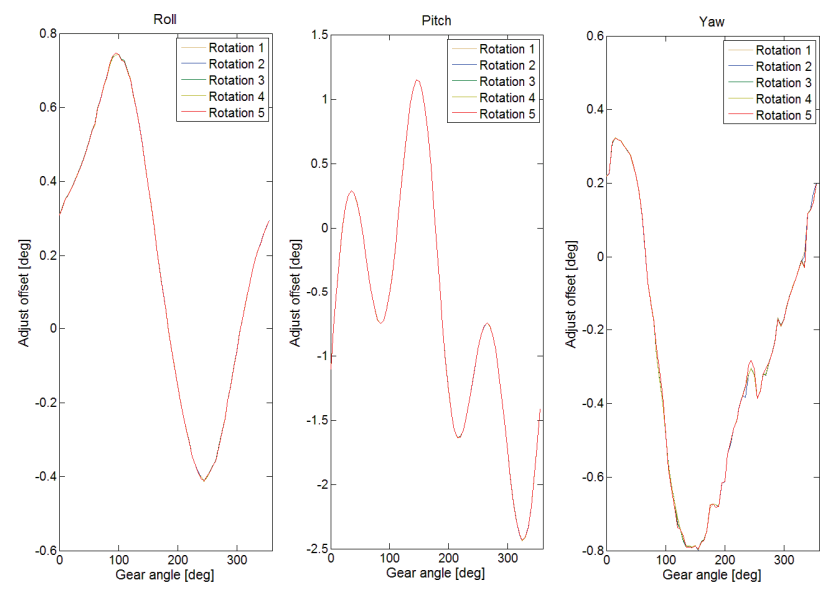

Figure 12. Angular correction boresights, repeated for 5 full circles

Aided by 5323 features, for any of the oblique images the relative angular offset to the reference image was determined. Figure 12 shows the angular offset between angles derived by formulas (1) to (3) and real angles determined by photogrammetric procedure. For any axis and any gear position, these values indicate the adjust-boresights. Repeat accuracies for all the five passages are shown in Table 2. Note, that all 361 images have been considered, thus the law of error propagation is integrated especially regarding the yaw angle.

\begin{tabular}{|l|l|l|}
\cline { 2 - 3 } \multicolumn{1}{c|}{} & $\begin{array}{l}\text { Mean standard } \\
\text { deviation }\end{array}$ & $\begin{array}{l}\text { Max. standard } \\
\text { deviation }\end{array}$ \\
\hline$\varphi($ roll $)$ & $0.0086 \mathrm{deg}$ & $0.016 \mathrm{deg}$ at photo 219 \\
\hline$\Theta($ pitch $)$ & $0.0078 \mathrm{deg}$ & $0.017 \mathrm{deg}$ at photo 003 \\
\hline$\psi($ yaw $)$ & $0.0359 \mathrm{deg}$ & $0.096 \mathrm{deg}$ at photo 003 \\
\hline
\end{tabular}

Table 2. Repeat accuracies, 5 times any of 72 gear positions

For investigated steps of $5 \mathrm{deg}$ the accuracy relating to the nadir image is less than 1 pixel $(2 \sigma)$. The sensor head consisting of gear, gimballed mount and two cameras complies with the requirements of a photogrammetric camera system.

The correction values are introduced into the matrix which transforms the orientations. Thus, the exterior orientation of the nadir camera can be converted into exterior orientation of the oblique camera and vice versa. The examination of MACSTumbleCam's accuracies will be continuatively analyzed during a separate publication.

\section{TEST FLIGHT}

In April 2012 one of few test flights were conducted using ATISS as carrier. Steered by the autopilot system, 10 parallel flight lines were passed (Figure 13). The target area was $0.5 \times 1$ $\mathrm{km}^{2}$ excluding turn radius. Operating height was ca. $200 \mathrm{~m}$ above ground level. 624 nadir images have been oriented by conventional AT. For any nadir image RTK GNSS position of focal point and roll, pitch, heading were given. Accuracy of direct georeferencing is shown in Table 3.

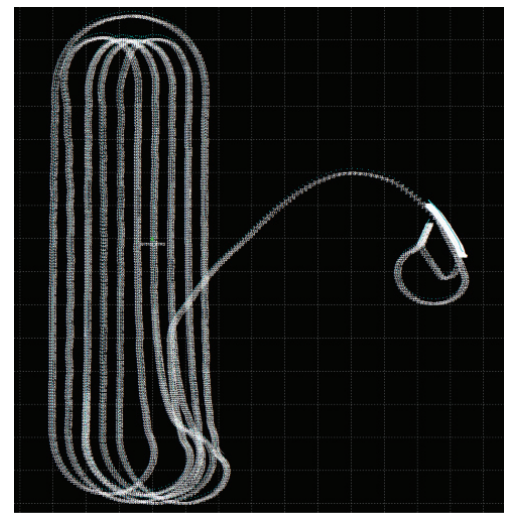

Figure 13. ATISS test-flight path

\begin{tabular}{|l|l|l|l|}
\hline \multicolumn{2}{|c|}{ RMS L1/L2 GNSS observations } & \multicolumn{2}{l|}{ RMS AHRS observations } \\
\hline $\mathrm{x}$ & $0.070[\mathrm{~m}]$ & Omega & $0.07[\mathrm{grd}]$ \\
\hline $\mathrm{y}$ & $0.083[\mathrm{~m}]$ & Phi & $0.06[\mathrm{grd}]$ \\
\hline $\mathrm{z}$ & $0.071[\mathrm{~m}]$ & Kappa & $0.11[\mathrm{grd}]$ \\
\hline
\end{tabular}

Table 3. Direct georeferencing accuracy of nadir camera

Figure 14 shows a single oblique image, one of multiple images used to texturize façades following the explained way. Based on the texturized 3D-model, interactive visualizations can be built. 
Figure 15 shows a screenshot of a 3D-model visualization. Pixel resolution is ca. $3 \mathrm{~cm}$ nadir and ca. $5.5 \mathrm{~cm}$ at vertical faces, respectively. Any pixel is assigned to a geodetic spatial coordinate. The virtual model is based on data exclusively by MACS-TumbleCam. Further geoinformation-specific examination like determination of roof geometries, tree counting, classifications etc. can be applied.

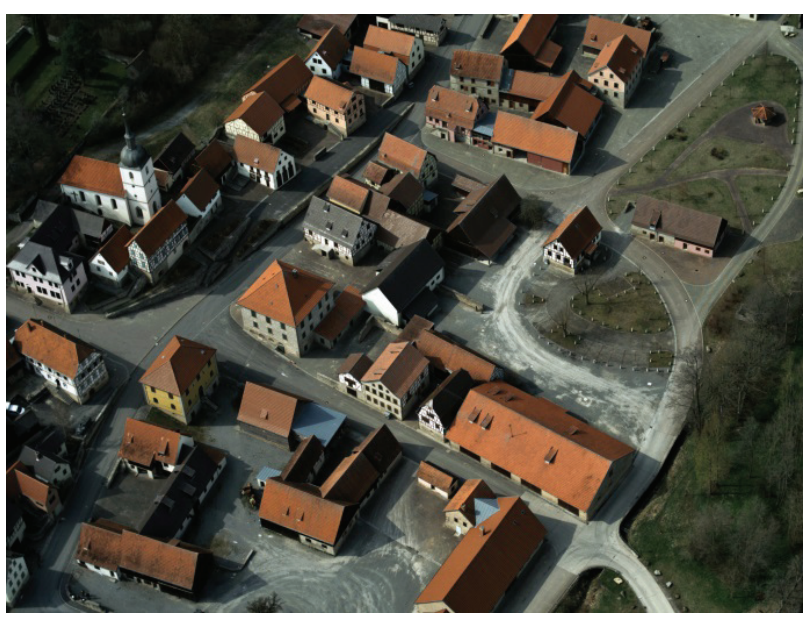

Figure 14. Single oblique image

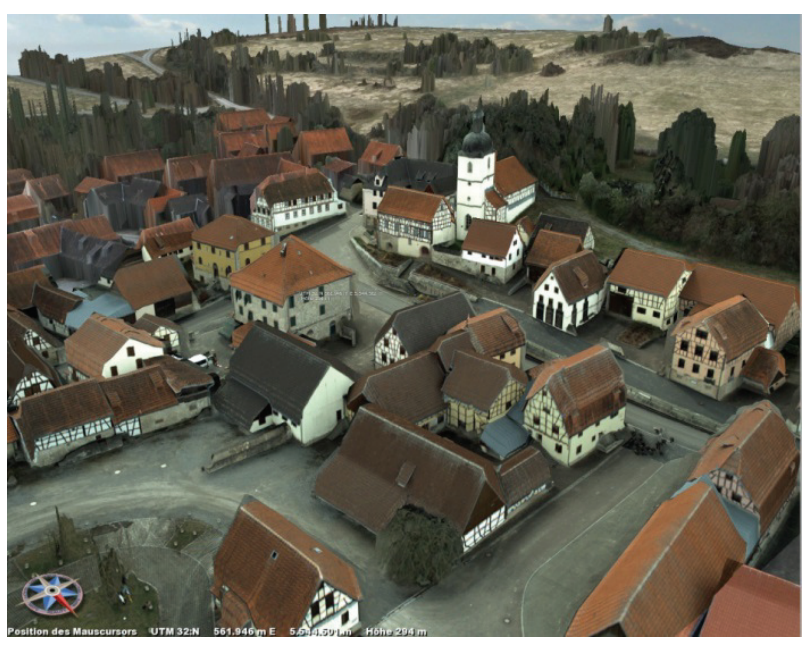

Figure 15. Screenshot of interactive 3D-visualization

\section{CONCLUSION AND FUTURE WORK}

A self-sustaining 3D-capable photogrammetric aerial camera system was shown, which claims less than $5 \mathrm{~kg}$ carrying capacity. A nadir camera was applied to determine high precision exterior orientation and to derive outputs like precise digital elevation models and orthomosaics. The single oblique camera covered all perspectives around nadir. It was used for automated, high resolution and pixel-accurate façade texture without aerotriangulation of it's images.

In further steps the on-the-fly crab angle compensation is examined, the motor assembly is intended to be significantly weight reduced and the gear is to be used to establish forward motion compensation.
Further development on the ATISS measurement drone is ongoing to improve safety operation by integrating a parachute rescue system and a triple redundant autopilot system.

\section{REFERENCES}

Küng, Strecha, Fua, Gurdan, Achtelik, Doth, Stumpf, 2011. Simplified building models extraction from ultra-light UAV imagery. International Archives of the Photogrammetry, Remote Sensing and Spatial Information Sciences, Volume XXXVIII-1/C22, 2011. ISPRS Zurich 2011 Workshop

Lehmann, Berger, Brauchle, Hein, Meissner, Pless, 2011. MACS -Modular airborne camera system for generating photogrammetric high-resolution products. PFG 6/2011, S. 435-446.

Li Z. \& Li Y. 2011. Photogrammetric recording of ancient buildings by using unmanned helicopters - cases in China. International Archives of the Photogrammetry, Remote Sensing and Spatial Information Sciences, Volume XXXVIII-1/C22, 2011. ISPRS Zurich 2011 Workshop.

Mathworks, 2013

http://www.mathworks.de/de/help/vision/ref/blockmatching.ht $\mathrm{ml}(24.05 .2013)$

Wenzel, Rothermel, Fritsch, Haala, 2013. Image acquisition and model selection for multi-view stereo. International Archives of the Photogrammetry, Remote Sensing and Spatial Information Sciences, Volume XL-5/W1, 2013.

Wieden \& Stebner, 2013. Referenzorientierung für Bilddaten aus Mehrkopfkamerasystemen. In: DGPF Tagungsband 22 / 2013, 22, Seiten 518-525.

\section{ACKNOWLEDGMENT}

All participating colleagues did a lot of great work to make this idea become real. The author of MACS-TumbleCam wants to thank especially the team of Neurorobotics Research Laboratory at the Humboldt-Universität $\mathrm{zu}$ Berlin who manufactured the sensor head and the motor control unit and the team of DLR OS-AK who assembled, software engineered and postprocessed all data.

Thanks also to the people from "Investitionsbank des Landes Brandenburg" ILB for their support of the SALSA project. 